\title{
Effect of Implementing Birth Plan on Women Childbirth Outcomes and Empowerment
}

\author{
Rehab Soliman Abd El Aliem , Afaf Mohamed Emam¹, Ahlam El Ahmady Sarhan ${ }^{2}$ \\ ${ }^{1}$ Obstetrics and Woman Health Nursing, Faculty of Nursing, Benha University, Benha, Egypt \\ ${ }^{2}$ Community Health Nursing, Faculty of Nursing, Benha University, Benha, Egypt
}

Email address:

Rehab.abdelalim@fnur.bu.edu.eg (R. S. A. E1 Aliem)

\section{To cite this article:}

Rehab Soliman Abd El Aliem, Afaf Mohamed Emam, Ahlam El Ahmady Sarhan. Effect of Implementing Birth Plan on Women Childbirth Outcomes and Empowerment. American Journal of Nursing Science. Vol. 9, No. 3, 2020, pp. 155-165. doi: 10.11648/j.ajns.20200903.25

Received: April 21, 2020; Accepted: May 11, 2020; Published: May 27, 2020

\begin{abstract}
Background: The birth plan raises women's knowledge, improves empowerment, and promotes childbirth outcomes. Aim of the study was to implement a birth plan and evaluate its effect on women childbirth outcomes and empowerment. Design: A quasi-experimental comparative design. Sampling: A purposive sample of 194 pregnant women was enrolled and equally allocated into two groups (the intervention group who engaged in a birth plan to receive planned care during childbirth, a control group who received routine hospital care) 97 women each. Setting: The study was conducted at the obstetrics outpatient clinic and in the delivery room of Benha University Hospital. Tools: four tools were used for data collection; A Structured Self-Administration Questionnaire, Birth plan fulfillment sheet, childbirth outcomes sheet, Childbirth related Empowerment Scale. Results: that there were highly significant difference in most items of designed birth plan care during 1st, 2nd and 3rd stage between control and study group $(\mathrm{P} \leq 0.001)$ and there was a significant decrease in mean $\pm \mathrm{SD}$ of 1st stage duration and the total duration of childbirth stages of the study group comparing to the control group $(\mathrm{P} \leq 0.05)$. Before implementing the birth plan, there was no statistical significance difference between control and study group regarding childbirth-related empowerment scale as $(\mathrm{p}>0.05)$ while after implementation, there were highly statistically significant differences regarding most items of birth-related empowerment scale as $(\mathrm{P} \leq 0.001)$. Conclusion: the birth plan has a higher implementation of designed childbirth care, a positive effect on maternal and fetal outcomes and there was a highly significant increase in the total women's empowerment scores after implementing birth plan $(p<0,001)$ compared to control group. Recommendation: Raising awareness of healthcare staff of the outpatient clinic, delivery ward to implement birth plan toward increasing childbirth empowerment.
\end{abstract}

Keywords: Birth Plan, Childbirth Outcomes, Empowerment

\section{Introduction}

The creation of a birth plan is an increasingly common part of a woman's antenatal childbirth preparation [1]. A birth plan is defined as a document created during pregnancy in preparation of childbirth to help the mother determine birth values, become acquainted with different options for childbirth, and develop a list of criteria to facilitate a supportive childbirth environment [2].

Adequate investment in preparation for birth is key to have uncomplicated childbirth, a birth plan is an important tool that valued childbirth care in the health system and empowers women participation in the childbirth care programs [3].

(WHO, 2016) [4] Reported that the birth plan serving for childbirth preparation, reducing the women's fears and providing tailored information which is missing in routine intrapartum care, so the implementation of birth plans is recommended as it encourages a more natural process of childbirth and avoids routine intrapartum procedures.

It is important for women to fully understand the provided intrapartum care if they want a childbirth with fewer interventions, unfortunately, prenatal education offered by most public hospitals is often a general program which does not aware pregnant women to the hospital protocol of care so it has negative effect on women empowerment toward 
making more informed decisions before giving birth [5].

The birth plan facilitates communication with health care staff, improves women's empowerment, and promotes childbirth outcomes [6]. The Birth Plan favors the ethical principle of autonomy and enhances women's control over the childbirth process therefore; it contributes to a positive effect on women's empowerment [7].

The key components of the birth plan include respecting women dignity, awareness the women of early signs of an emergency, labor begins on its own, a plan for a birth attendant, no restriction on oral fluid, freedom of movement throughout childbirth, and proper management during childbirth stages [8]. Many prenatal care innovations recommended pregnant empowerment is an innovative mechanism that brings favorable birth outcomes by involving women in participating in birth plan formulation and implementation [9].

Empowerment defined as the process of enhancing women's ability to make purposive choices and to transform those choices into desired actions and outcomes [10]. Empowerment achieved the implementation of the birth plan through several sequential components as self-efficacy, future image, self-esteem, support and assurance from birth supports and joy of adding to new family [11].

On the other hand, some studies documented a lower rate of cesarean sections and better birth outcomes if women utilized birth plans compared to more reported complications with routine care [12]. However, the influence of birth plans on birth outcomes need further well studies, a body of data demonstrates that birth preparedness, positive women experiences and empowerments are associated with improved maternal outcomes [13].

Maternity nurse is the first skilled staff who has contact with pregnant women and plays a crucial role throughout the prenatal period raising the pregnant woman empowerment by providing appropriate information, prepare woman physically and emotionally, stress on their rights for promoting birth outcomes and provide chances for social support with health care staff to implement the designed birth plan [14].

The maternity nurse takes the responsibility of educating women about birth plans and directing nursing care to labor women so that they can help the women achieve safe childbirth process and positive outcomes [15]. Once the nurse understands women's preferences, building a trust relationship and then provides appropriate information and communication to support their preferences [16].

\subsection{Significance of the Study}

In Egypt, 1400 women and $50 \%$ of their newborns die each year due to pregnancy and childbirth complications which need further efforts to be applied as programs or approaches to improve maternal health issues [17]. Antenatal childbirth preparation is often seen as a doorway to women's health through education, communication, and empowerment of women which were the main components of the birth plan. Despite that, it isn't applied efficiently in
Egypt and limited to private maternity hospitals so women in public hospitals feel unsupported because nurses and doctors focus more on providing routine care rather than face-to-face care.

Birth plan implementation not a burden on health care staff, vice versa it directs nursing practices toward women`s needs and aware women about emergency signs to be identified as early as possible, researches proved that when maternity hospital policies implemented birth plan component, they deliver a comprehensive and quality childbirth care.

The birth plans become more successful in promoting birth outcomes by all health care staff including maternity nurses as they communicate, educate women about childbirth and facilitate greater empowerment lead to improvements in their health, particularly in areas where disparities are highest such as maternal mortality.

There are limited researches in Egypt that exist on the topic of birth plans and this is the first study examined its effect on childbirth empowerment. From this, more researches need to be conducted to better understand the effect of the birth plans in improving birth outcomes also, to promote women empowerment more positively. This wouldn't be happened by unless the health care staff adopting and educating the women about birth plans in preparation for childbirth and hospital policies supporting this approach. So the present study is looking to evaluate the effect of implementing a birth plan on women childbirth outcomes and empowerment.

\subsection{Aim of the Study}

The current study was aimed to evaluate the effect of implementing a birth plan on women childbirth outcomes and empowerment

\subsection{Research Hypotheses}

Hypothesis 1: Pregnant women who engaged in a birth plan will receive more designed child birth care than those who not engaged in the birth plan.

Hypothesis 2: Pregnant women who engaged in a birth plan will exhibit better childbirth outcomes than those participants who not engaged in the birth plan.

Hypothesis 2: Pregnant women who engaged in a birth plan have a higher level of childbirth-related empowerment than those who not engaged in the birth plan.

\section{Subject and Methods}

\subsection{Research Design}

A quasi-experimental research design was utilized.

\subsection{Setting}

The study was conducted at obstetrics outpatient clinic and in the delivery room at Benha University Hospital. This setting is the official hospital affiliated to Benha University 
with a high rate of women undergoing childbirth.

\subsection{Sample Type and Size}

A convenience sample of 194 pregnant women was enrolled and equally allocated into two groups (intervention and control group) They were recruited from the previously mentioned setting according to the following criteria: age 18 years or more, primigravida, gestational age from 36 to 40 weeks, normal pregnancy with (singleton pregnancy\& cephalic presentation), chosen delivered normal childbirth at Benha university hospital and read \& write. Exclusion criteria included suspected placental abruption, and/or any contraindications to vaginal delivery were ineligible.

\subsection{Tools of Data Collection}

Four main tools were used for data collection.

\subsubsection{The Tool I: A Structured Self-Administration Questionnaire}

This tool was designed by the researchers after reviewing related literature; it was written in a simple Arabic language and included demographic characteristics of the studied women as age, educational level, occupation, residence, and monthly income, and telephone number, besides, gestational age at enrollment.

\subsubsection{Tool II: Birth Plan Fulfillment Sheet}

It included two parts Part A- Birth plan expectations sheet which was prepared based on the standard childbirth worksheet for [18] in the form of open-closed questions. And then translated $\&$ introduced to each a pregnant woman in the intervention group to choose and filled birth plan in the outpatient clinic in order to assess their expectations during childbirth (as respecting dignity, presence of birth attendants, no restriction on oral fluid, encourage movement and proper management during childbirth).

Part B- Childbirth characteristics sheet that was adopted from [19] to evaluate the implementation of designed birth plan care during childbirth. It was recorded by the researchers and included care during 1st stage (6 items) such as (complete history taking, physical examination, the partograph, fetal monitoring, hydration, and movement), care during 2nd stage (3items) such as (type of pushing, position of delivery and perineal condition) care after delivery (3items) such as (immediate baby care, Apgar score, carrying and dressing the baby, breastfeeding and hospital discharge). Each item was scored (1) for done each step while (0) score was given for not done. The higher scores indicated better implementation of a birth plan during childbirth.

\subsubsection{Tool III: Childbirth Outcomes Sheet}

The childbirth outcomes sheet was used to assess childbirth duration outcomes as (onset of childbirth, duration of childbirth), maternal outcomes as (mode of delivery, presence of complications, childbirth experience and hospitalization days) and fetal outcomes which included (Apgar score at $1^{\text {st }}, 5^{\text {th }}$ minute and baby weight).

\subsubsection{Tool IV: Childbirth Empowerment Scale (CES)}

The childbirth empowerment Scale (CES) was adopted from [20] and translated into the Arabic language to assess pregnant women's childbirth-related empowerment and sense of control over their birth plan. The CES consisted of 25 items covering four subscales; self-efficacy (6 items), future image (6 items), self-esteem ( 5 items), support and assurance from others (4 items), and joy of adding to a new family (including 4items). It was filled before and after implementing the designed birth plan.

Scoring system

The CES score is a total of the items based on 3- Likert scale rating, from 1 "disagree" 2 "to what extent" 3 "agree". The total minimum score was 25 and the maximum score was 75 . High empowerment were $>75 \%$ ( $>56.25$ degree) of total score, Moderate empowerment range from $>60-75 \%$ ( $>$ 45-56.25 degree) of total score and Low empowerment below $60 \%$ ( $<45$ degree $)$ of total score.

\subsection{Tools Validity and Reliability}

The tools were reviewed for appropriateness and comprehensives of contents through a panel of three experts in the field of maternity nursing and obstetric medicine. The panel ascertained the content validity of the tools II and IV. The reliability was measured with Cronbach's Alpha coefficient test, the internal consistency of the observational childbirth characteristic equal 0.75 , CES equal 0.90 , and birth outcomes sheet equal 0.87 .

\subsection{Ethical Considerations}

Informed oral consent was obtained from every participant recruited in the study after an explanation of nature and the aim of the study. The participants were assured that all data are used only for research purposes. Each participant was informed that participation is voluntary and has the right to refuse or withdraw at any time without any interference with the care provided. Participants' anonymity and confidentiality were secured.

\subsection{Pilot Study}

A pilot study was carried out on 10\% (20 pregnant women) of the total sample size to ascertain the clarity and applicability of the tools, estimate the time required to complete the tools, and detect any obstacles that may be encountered to the researchers during the study process. No modifications were done, thus these pregnant women were included within the main study sample.

Birth plan component:

A birth plan was adopted by $[19,21]$ translated into the Arabic language and adapted by the researchers based on women choices, it consisted of women preferences such as (clothes, transport arrangements, health care providers involved or present at the birth, mode of delivery, method for starting childbirth, support person and pain relief measures as analgesia), besides instructional content (leaflet) regarding early emergency signs during late pregnancy, obstetric care 
during childbirth stages " $1{ }^{\text {st }}, 2^{\text {nd }}$ and $3^{\text {rd }}$ stage".

\subsection{Procedure}

The study was carried out from the beginning of March 2018 to the end of September 2018, covering a period of six months. Official approval to conduct this study was obtained from the Dean of Faculty of Nursing to Director of Benha University Hospital and the Manager of Obstetrics and Emergency Department. The researchers visited the previously mentioned setting three days per week (Saturday, Thursday and Tuesday) from $9.00 \mathrm{a} . \mathrm{m}$. to $1.00 \mathrm{p}$.m. The average number of participants interviewed per week was 4-5 women.

The researchers interviewed, introduced themselves to each woman with the inclusion criteria to participate in the study during her antenatal follow-up visit (delivery preparation visit) in the outpatient clinic, and explained all information about the study aim, duration, and activities, and then written consent was obtained. The researchers obtained the data of the interviewing questionnaire from both groups and asked the participants (intervention \&control) to telephone them to determine the time of childbirth.

For the control group: as the childbirth started they have received routine care (without writing birth plan) as care during the first stage of labor in attendance of researchers, which included (administrating intravenous fluids, auscultating fetal heart, taking vital signs, assessment uterine contraction, vaginal examination, and oxytocin augmentations), care of the second stage included perform episiotomy, delivery of head \&baby and then active care of the third stage without any additional interventions or instructions.

For the intervention group: In the delivery preparation visit, the researchers continue to introduce part A- Birth plan expectations sheet to pregnant woman to choose and fill it, explanation and discussion about childbirth birth plan was conducted with pregnant women, the researchers focused sequentially on empowerment about birth plan components as (early emergency signs in late pregnancy and labor, nutrition during labor, preparation \& childbirth care "1st, 2nd and 3rd stage", early postpartum care, breastfeeding\& immediate care of the newborn) and given the Arabic leaflet on the mentioned topics. The written birth plan was given to health care providers (obstetrician \&maternity nurse) to discuss the feasibility \& barriers of implementing a birth plan.

Finally, when the childbirth started, the researchers had evaluated the implementation of birth plan care through tool II-part B characteristic of childbirth sheet, then after childbirth complete the tool III and IV for both control and intervention group.

The average time for completion tools was around $30-45$ minutes, divided as (5 minutes) for the tool I, (15-20 minutes) for tool II, (5-10 minutes) for tool III, and (5-10 minutes) for tool IV.

\subsection{Statistical Analysis}

Data were verified before computer entry. Statistical Package for Social Sciences (SPSS version 22.0) was used, followed by data analysis and tabulation. Descriptive statistics applied (frequency, percentages, mean and standard deviation,). Tests of significance (Chi-square, Fisher Exact Test used when the cells have expected count less than 5 and independent t-test) were used for comparison between the groups and to test the study hypotheses. A statistically significant difference was considered at $\mathrm{p}$-value $\leq 0.05$, a highly statistically significant difference was considered at $\mathrm{p}$ value $\leq 0.001$. And no statistically significant difference was considered at $p$-value $>0.05$.

\subsection{Limitations of the Study}

This study has two limitations; first, the lack of national researches that studies the current research topic. Second, challenging to conduct the study in a public hospital.

\section{Results}

Table 1 demonstrates that the mean age $\pm \mathrm{SD}$ of the control group were $25.6 \pm 4.96$ and the study group were $27.2 \pm 5.39$, (54.6\%) of the control group lived in rural areas in compare to $(58.8 \%)$ of the study group, $(54.6 \%)$ of the control group had secondary education in compare to $(50.5 \%)$ of the study group, and $(53.6 \%)$ of the control group were housewife comparing to $(52.6 \%)$ of the study group. also, the gestational age of the control group was $35.7 \pm 0.57$ and the study group was $35.5 \pm 0.54$ and there were no statistically significant differences between both groups about demographic data $(p>0.05)$.

Table 2 displays that there were highly significant differences in most items of designed birth plan care during 1 st, 2nd and 3rd stage between control and study group ( $\mathrm{P} \leq$ $0.001)$.

Table 3 denotes that there was a significant decrease in mean $\pm \mathrm{SD}$ of $1^{\text {st }}$ stage duration and the total duration of childbirth stages of the study group comparing to the control group as $(\mathrm{P} \leq 0.05)$.

Table 4 elaborates $77.3 \%$ of study group delivered vaginal delivery comparing to $58.8 \%$ of control group, $75.3 \%$ of study group had satisfactory experience of childbirth compared to $42.3 \%$ of control group and $17.8 \%$ of study group had complications comparing to $27.8 \%$ of control group with highly statistically significant difference as $(\mathrm{P} \leq$ $0.001)$.

Figure 1 illustrates that the majority of study and control groups $(77.3 \%, 71.1 \%)$ respectively had normal Apgar scores after childbirth.

Figure 2 reveals that the baby weight at birth of the study and control groups were relatively similar and normal.

Table 5 portrays there was no statistical significance difference between control and study group regarding items of birth-related empowerment scale before implementing a birth plan ( $p>0.05)$.

Figure 3 portrays that the $(41.2 \%, 47.4)$ of the control \& study studied group respectively had moderate total childbirth empowerment scores before the intervention.

Table 6 displays there was a highly statistically significant 
difference between control and study groups regarding most items of childbirth-related empowerment scale $(\mathrm{P} \leq 0.001)$.

Figure 4 portrays that the $(89.7 \%, 27.8 \%)$ of the control \&study groups respectively had high total childbirth empowerment scores after implementation.

Table 1. Number and percentage distribution of the studied women according to their demographic data ( $n=194)$.

\begin{tabular}{|c|c|c|c|c|c|c|}
\hline \multirow{2}{*}{ Socio-Demographic data } & \multicolumn{2}{|c|}{ Control group $(n=97)$} & \multicolumn{2}{|c|}{ Study group $(n=97)$} & \multirow{2}{*}{$\mathbf{X}^{2} /$ FET } & \multirow{2}{*}{ p-value } \\
\hline & No & $\%$ & No & $\%$ & & \\
\hline \multicolumn{7}{|l|}{ Age } \\
\hline $18-<25$ & 53 & 54.6 & 40 & 41.2 & \multirow{3}{*}{3.55} & \multirow{3}{*}{$0.169^{\mathrm{ns}}$} \\
\hline $25-<34$ & 22 & 22.7 & 27 & 27.8 & & \\
\hline$>35$ years & 22 & 22.7 & 30 & 30.9 & & \\
\hline Mean \pm SD & \multicolumn{2}{|l|}{$25.6 \pm 4.96$} & \multicolumn{2}{|l|}{$27.2 \pm 5.39$} & $\mathrm{t}=1.810$ & $0.072^{\mathrm{ns}}$ \\
\hline \multicolumn{7}{|l|}{ Residence } \\
\hline Rural & 53 & 54.6 & 57 & 58.8 & 1.36 & $0.243^{\mathrm{ns}}$ \\
\hline \multicolumn{7}{|l|}{ Level of education } \\
\hline Basic education & 15 & 15.5 & 21 & 21.7 & \multirow{3}{*}{4.86} & \multirow{3}{*}{$0.427^{\mathrm{ns}}$} \\
\hline Secondary education & 53 & 54.6 & 49 & 50.5 & & \\
\hline higher education & 29 & 29.9 & 27 & 27.8 & & \\
\hline \multicolumn{7}{|l|}{ Occupation } \\
\hline Housewife & 52 & 53.6 & 51 & 52.6 & 1.01 & $.315^{\mathrm{ns}}$ \\
\hline
\end{tabular}

$\mathrm{Ns}=$ no statistically significant difference $(\mathrm{p}>0.05), \mathrm{t}=$ independent $\mathrm{t}$-test $£=$ Fisher Exact Test.

Table 2. Distribution of the studied women regarding childbirth characteristics of care $\left(1^{\text {st }}, 2^{\text {nd }} \& 3^{\text {rd }}\right.$ stage $)(n=194)$.

\begin{tabular}{|c|c|c|c|c|}
\hline \multirow{2}{*}{ Birth plan care } & \multirow{2}{*}{$\begin{array}{l}\text { Control group }(n=97) \\
\text { No }(\%)\end{array}$} & \multirow{2}{*}{$\begin{array}{l}\text { Study group }(n=97) \\
\text { No }(\%)\end{array}$} & \multirow{2}{*}{$\mathbf{X}^{2}$} & \multirow{2}{*}{ p-value } \\
\hline & & & & \\
\hline \multicolumn{5}{|l|}{$1^{\text {st }}$ stage } \\
\hline Obtain complete history taking & $76(78.4)$ & $97(100.0)$ & 23.54 & $.000 * *$ \\
\hline Perform Physical examination & $85(87.6)$ & $89(91.8)$ & 0.89 & $.345^{\mathrm{ns}}$ \\
\hline Provide emotional support in childbirth & $41(42.3)$ & $86(88.7)$ & 46.16 & $.000 * *$ \\
\hline Continuous fetal monitoring & $44(45.4)$ & $85(87.6)$ & 38.89 & $.000 * *$ \\
\hline Applying partogram & $47(48.5)$ & $74(76.3)$ & 16.01 & $.000 * *$ \\
\hline Encourage moving during labor & $52(53.6)$ & $74(76.3)$ & 10.95 & $.001 * *$ \\
\hline Allow Frequent change of positions & $66(68.0)$ & $85(87.6)$ & 10.78 & $.001 * *$ \\
\hline Provide Pain relieve measures & $68(70.1)$ & $97(100.0)$ & 34.09 & $.000 * *$ \\
\hline $\begin{array}{l}\text { Administer oxytocin in late dilatation } \\
2^{\text {nd }} \text { stage }\end{array}$ & $63(64.9)$ & $85(87.6)$ & 56.53 & $.000 * *$ \\
\hline Encourage pushing & $97(100.0)$ & $87.6(85)$ & 12.79 & $.000 * *$ \\
\hline Perform Episiotomy & $97(100.0)$ & $62.9(61)$ & 44.2 & $.000 * *$ \\
\hline \multicolumn{5}{|l|}{$3^{\text {rd }}$ stage } \\
\hline Delay cord clamping & $44(45.4)$ & $74(76.3)$ & 72.9 & $.000 * *$ \\
\hline Facilitate Early skin to skin contact & $40(41.2)$ & $97(100.0)$ & 80.71 & $.000 * *$ \\
\hline
\end{tabular}

Ns: no statistically significant difference $(\mathrm{p}>0.05),{ }^{* *}$ A highly statistically significant difference $(\mathrm{P} \leq 0.001)$.

Table 3. Comparison of the mean and standard deviation of childbirth duration among studied women ( $n=194)$.

\begin{tabular}{|c|c|c|c|c|c|c|}
\hline & \multicolumn{2}{|c|}{ Control group $(n=97)$} & \multicolumn{2}{|c|}{ Study group $(n=97)$} & \multirow{2}{*}{ T- test } & \multirow{2}{*}{ p-value } \\
\hline & Mean & \pm SD & Mean & \pm SD & & \\
\hline $1^{\text {st }}$ stage & 11.66 & 3.09 & 10.54 & 3.11 & 6.08 & $0.01 *$ \\
\hline $2^{\text {nd }}$ stage & 1.87 & 0.36 & 2.04 & 0.61 & 3.78 & $0.17^{\mathrm{ns}}$ \\
\hline $3^{\text {rd }}$ stage & 0.26 & 0.51 & 0.38 & 0.12 & 1.45 & $.150^{\mathrm{ns}}$ \\
\hline Total duration & 13.79 & 3.96 & 12.96 & 3.84 & 8.87 & $0.05^{*}$ \\
\hline
\end{tabular}

${ }^{\mathrm{NS}}=$ no statistically significant difference $(\mathrm{p}>0.05),{ }^{*}$ A statistically significant difference $(\mathrm{P} \leq 0.05)$.

Table 4. Comparison of maternal outcomes among studied women ( $n=194)$.

\begin{tabular}{|c|c|c|c|c|c|c|c|}
\hline \multirow{2}{*}{ Items } & & \multicolumn{2}{|c|}{ Control group $(n=97)$} & \multicolumn{2}{|c|}{ Study group $(n=97)$} & \multirow{2}{*}{$\mathbf{X}^{2}$} & \multirow{2}{*}{ p-value } \\
\hline & & No & $\%$ & No & $\%$ & & \\
\hline \multirow{2}{*}{ Mode of delivery } & Vaginal delivery & 57 & 58.8 & 75 & 77.3 & \multirow{2}{*}{31.84} & \multirow{2}{*}{$.000 * *$} \\
\hline & Caesarean section & 40 & 41.2 & 22 & 22.7 & & \\
\hline \multirow{2}{*}{ Onset of childbirth } & Spontaneous & 29 & 29.9 & 85 & 87.6 & \multirow{2}{*}{7.68} & \multirow{2}{*}{$.006^{*}$} \\
\hline & Induced & 64 & 66 & 12 & 12.4 & & \\
\hline \multirow{2}{*}{ Childbirth experience } & Satisfactory experience & 41 & 42.3 & 73 & 75.3 & \multirow{2}{*}{9.87} & \multirow{2}{*}{$.000 * *$} \\
\hline & Un satisfactory experience & 56 & 57.7 & 24 & 24.7 & & \\
\hline
\end{tabular}




\begin{tabular}{|c|c|c|c|c|c|c|c|}
\hline \multirow{2}{*}{ Items } & & \multicolumn{2}{|c|}{ Control group $(\mathrm{n}=97)$} & \multicolumn{2}{|c|}{ Study group $(n=97)$} & \multirow{2}{*}{$\mathbf{X}^{2}$} & \multirow{2}{*}{ p-value } \\
\hline & & No & $\%$ & No & $\%$ & & \\
\hline \multirow{3}{*}{ Presence of complications } & Abnormal fetal heart rate & 23 & 23.7 & 16 & 16.5 & \multirow{3}{*}{16.45} & \multirow{3}{*}{$.001 * *$} \\
\hline & Meconium stained liquor & 4 & 4.1 & 1 & 1.3 & & \\
\hline & Perineal lacerations & 18 & 14.4 & 0 & 0 & & \\
\hline \multirow{2}{*}{ Hospitalization days } & One day & 85 & 87.6 & 87 & 89.7 & \multirow{2}{*}{0.205} & \multirow{2}{*}{$.651^{\mathrm{ns}}$} \\
\hline & Two days & 12 & 12.4 & 10 & 10.3 & & \\
\hline
\end{tabular}

${ }^{\mathrm{N} s=}$ no statistically significant difference $(\mathrm{p}>0.05),{ }^{* *}$ A highly statistically significant difference $(\mathrm{P} \leq 0.001)$.

Table 5. Comparison of childbirth empowerment scale between the studied pregnant women (control \&study group) before implementation ( $n=194)$.

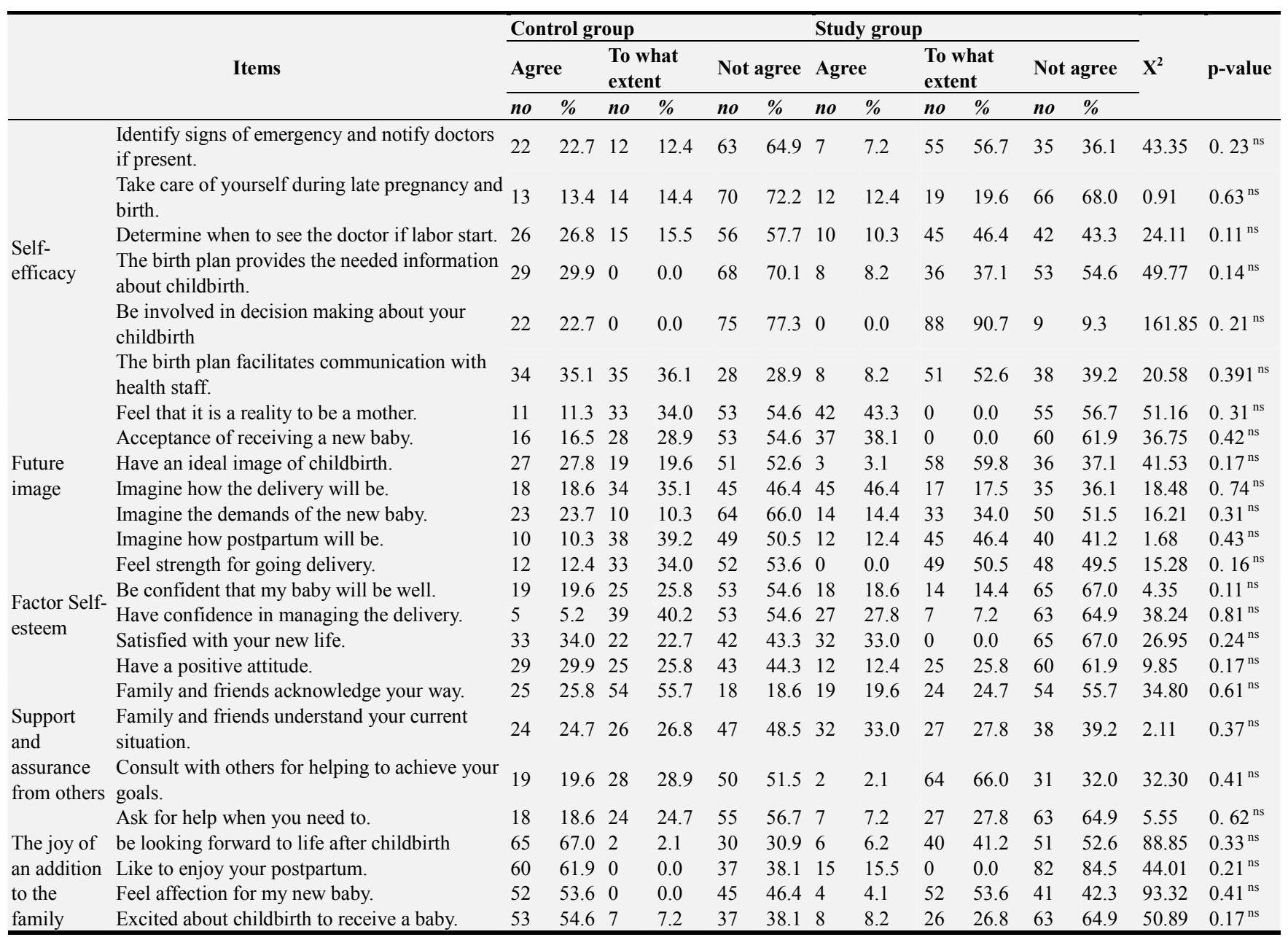

ns, a statistically significant difference $(\mathrm{p}>0.05)$.

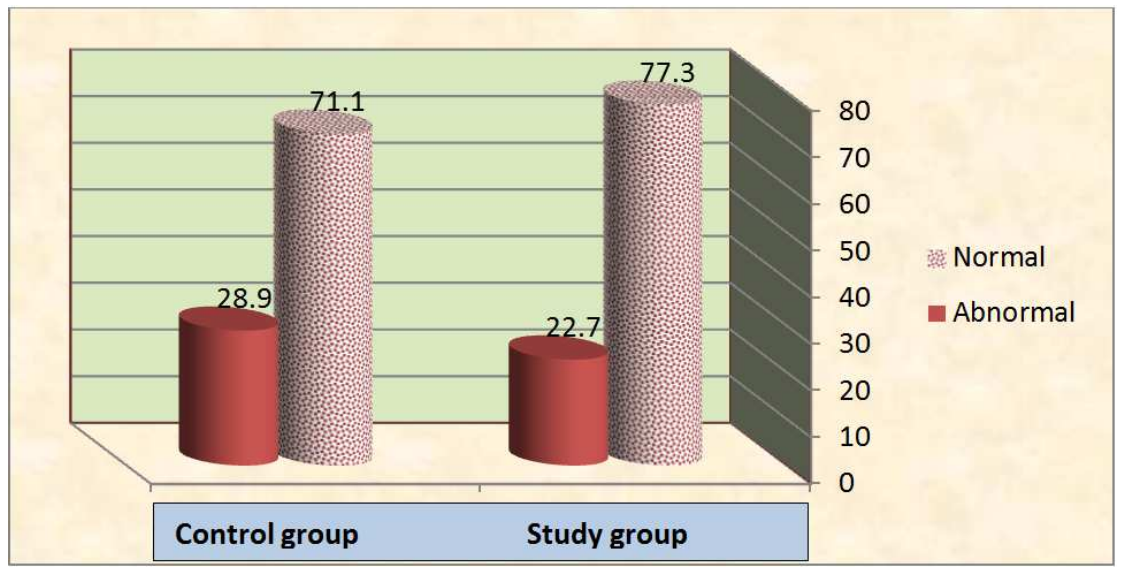

Figure 1. Frequency distribution of studied women regarding fetal outcomes (Apgar score) (n=194). 
Table 6. Comparison of childbirth empowerment scale between the studied pregnant women (control \&study) after implementation ( $n=194)$.

\begin{tabular}{|c|c|c|c|c|c|c|c|c|c|c|c|c|c|c|c|}
\hline \multirow{3}{*}{ Items } & & \multicolumn{6}{|c|}{ Control group } & \multicolumn{6}{|c|}{ Study group } & \multirow{3}{*}{$X^{2}$} & \multirow{3}{*}{ p-value } \\
\hline & & \multicolumn{2}{|c|}{ Agree } & \multicolumn{2}{|c|}{$\begin{array}{l}\text { To what } \\
\text { extent }\end{array}$} & \multicolumn{2}{|c|}{ Not agree } & \multicolumn{2}{|c|}{ Agree } & \multicolumn{2}{|c|}{$\begin{array}{l}\text { To what } \\
\text { extent }\end{array}$} & \multicolumn{2}{|c|}{ Not agree } & & \\
\hline & & no & $\%$ & no & $\%$ & no & $\%$ & no & $\%$ & no & $\%$ & no & $\%$ & & \\
\hline \multirow{6}{*}{$\begin{array}{l}\text { Self- } \\
\text { efficacy }\end{array}$} & $\begin{array}{l}\text { Identify signs of emergency and notify doctor } \\
\text { if present }\end{array}$ & 97 & 100.0 & 0 & 0.0 & 0 & 0.0 & 7 & 7.2 & 35 & 36.1 & 55 & 56.7 & 17.8 & $.000 * *$ \\
\hline & $\begin{array}{l}\text { Take care of yourself during late pregnancy } \\
\text { and birth. }\end{array}$ & 55 & 56.7 & 32 & 33.0 & 10 & 10.3 & 15 & 15.5 & 60 & 61.9 & 22 & 22.7 & 48.0 & $.000 * *$ \\
\hline & Determine when to see the doctor if labor start. & 87 & 89.7 & 10 & 10.3 & 0 & 0.0 & 15 & 15.5 & 47 & 48.5 & 35 & 36.1 & 19.8 & $.000 * *$ \\
\hline & $\begin{array}{l}\text { The birth plan provides the needed } \\
\text { information about childbirth. }\end{array}$ & 77 & 79.4 & 20 & 20.6 & 0 & 0.0 & 20 & 20.6 & 57 & 58.8 & 20 & 20.6 & 71.2 & $.000 * *$ \\
\hline & $\begin{array}{l}\text { Be involved in decision making about your } \\
\text { childbirth }\end{array}$ & 87 & 89.7 & 10 & 10.3 & 0 & 0.0 & 0 & 0.0 & 14 & 14.4 & 83 & 85.6 & 17.6 & $.000 * *$ \\
\hline & $\begin{array}{l}\text { The birth plan facilitates communication with } \\
\text { health staff }\end{array}$ & 87 & 89.7 & 10 & 10.3 & 0 & 0.0 & 27 & 27.8 & 43 & 44.3 & 27 & 27.8 & 79.1 & $.000 * *$ \\
\hline \multirow{5}{*}{$\begin{array}{l}\text { Future } \\
\text { image }\end{array}$} & Feel that it is a reality to be a mother. & 87 & 89.7 & 10 & 10.3 & 0 & 0.0 & 87 & 89.7 & 10 & 10.3 & 0 & 0.0 & 10.4 & $.001 * *$ \\
\hline & Have an ideal image of childbirth. & 75 & 77.3 & 22 & 22.7 & 0 & 0.0 & 13 & 13.4 & 42 & 43.3 & 42 & 43.3 & $91 . .9$ & $.000 * *$ \\
\hline & Imagine how the delivery will be. & 87 & 89.7 & 7 & 7.2 & 3 & 3.1 & 34 & 35.1 & 56 & 57.7 & 7 & 7.2 & 85.9 & $.000 * *$ \\
\hline & Imagine the demands of the new baby. & 65 & 67.0 & 22 & 33.0 & 10 & 10.3 & 64 & 66.0 & 33 & 34.0 & 0 & 0.0 & 0.02 & $.879^{\mathrm{ns}}$ \\
\hline & Imagine how postpartum will be. & 89 & 91.7 & 8 & 8.2 & 0 & 0.0 & 26 & 26.8 & 43 & 44.3 & 28 & 28.9 & 11.9 & $.000 * *$ \\
\hline \multirow{5}{*}{$\begin{array}{l}\text { Factor } \\
\text { Self- } \\
\text { esteem }\end{array}$} & Feel strength for going delivery. & 67 & 69.1 & 0 & 0.0 & 0 & 0.0 & 7 & 7.2 & 37 & 38.1 & 53 & 54.6 & 16.8 & $.000 * *$ \\
\hline & Be confident that my baby will be well. & 77 & 79.4 & 10 & 10.3 & 10 & 10.3 & 48 & 49.5 & 41 & 42.3 & 8 & 8.2 & 65.5 & $.000 * *$ \\
\hline & Have confidence in managing the delivery. & 90 & 92.8 & 7 & 7.2 & 0 & 0.0 & 27 & 27.8 & 63 & 64.9 & 7 & 7.2 & 19.5 & $.000 * *$ \\
\hline & Satisfied with your new life. & 87 & 89.7 & 10 & 10.3 & 0 & 0.0 & 69 & 71.1 & 28 & 28.9 & 0 & 0.0 & 10.6 & $.001 * *$ \\
\hline & Have a positive attitude. & 75 & 77.3 & 22 & 22.7 & 0 & 0.0 & 48 & 49.5 & 49 & 50.5 & 0 & 0.0 & 16.1 & $.000 * *$ \\
\hline \multirow{3}{*}{$\begin{array}{l}\text { Support } \\
\text { from } \\
\text { others }\end{array}$} & Family and friends acknowledge your way. & 75 & 77.3 & 22 & 22.7 & 0 & 0.0 & 45 & 46.4 & 45 & 46.4 & 7 & 7.2 & 22.3 & $.000 * *$ \\
\hline & $\begin{array}{l}\text { Family and friends understand your current } \\
\text { situation. }\end{array}$ & 97 & 100.0 & 0 & 0.0 & 0 & 0.0 & 52 & 53.6 & 45 & 46.4 & 0 & 0.0 & 58.5 & $.000 * *$ \\
\hline & $\begin{array}{l}\text { Consult with others for helping to achieve } \\
\text { your goals. }\end{array}$ & 87 & 89.7 & 10 & 10.3 & 0 & 0.0 & 14 & 14.4 & 35 & 36.1 & 48 & 49.5 & 114.6 & $.000 * *$ \\
\hline \multirow{3}{*}{$\begin{array}{l}\text { The joy of } \\
\text { an addition } \\
\text { to the } \\
\text { family }\end{array}$} & Like to enjoy your postpartum. & 75 & 77.3 & 22 & 22.7 & 0 & 0.0 & 50 & 51.5 & 47 & 48.5 & 0 & 0.0 & 14.0 & $.000 * *$ \\
\hline & Feel affection for my new baby. & 97 & 100.0 & 0 & 0.0 & 0 & 0.0 & 40 & 41.2 & 41 & 42.3 & 16 & 16.5 & 80.7 & $.000 * *$ \\
\hline & Excited about childbirth to receive a baby. & 97 & 100.0 & 0 & 0.0 & 0 & 0.0 & 40 & 41.2 & 57 & 58.8 & 0 & 0.0 & 80.7 & $.000 * *$ \\
\hline
\end{tabular}

${ }^{\mathrm{n} s}$ no statistically significant difference $(\mathrm{p}>0.05), * *$ A highly statistically significant difference $(\mathrm{P} \leq 0.001)$.

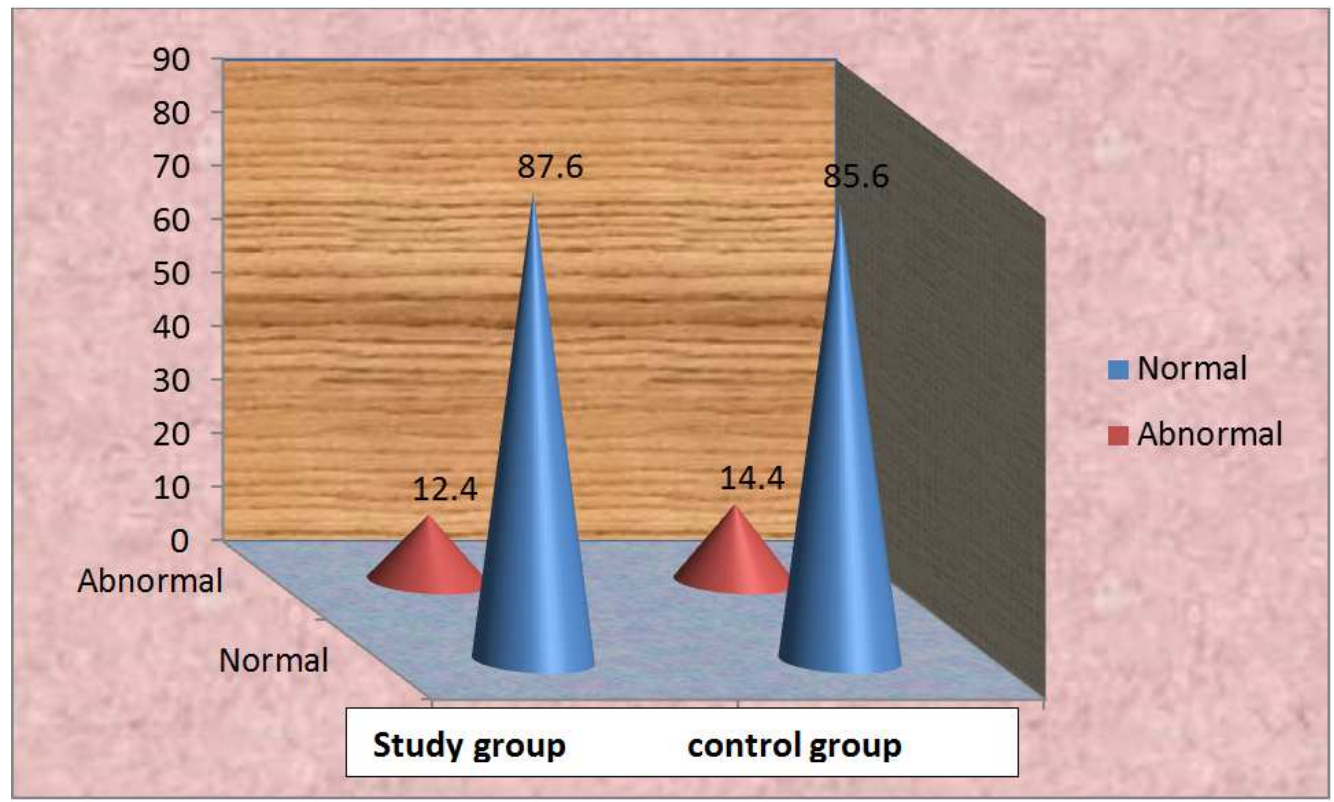

Figure 2. Frequency distribution of studied women 's regarding fetal outcomes (baby weight) ( $n=194)$. 


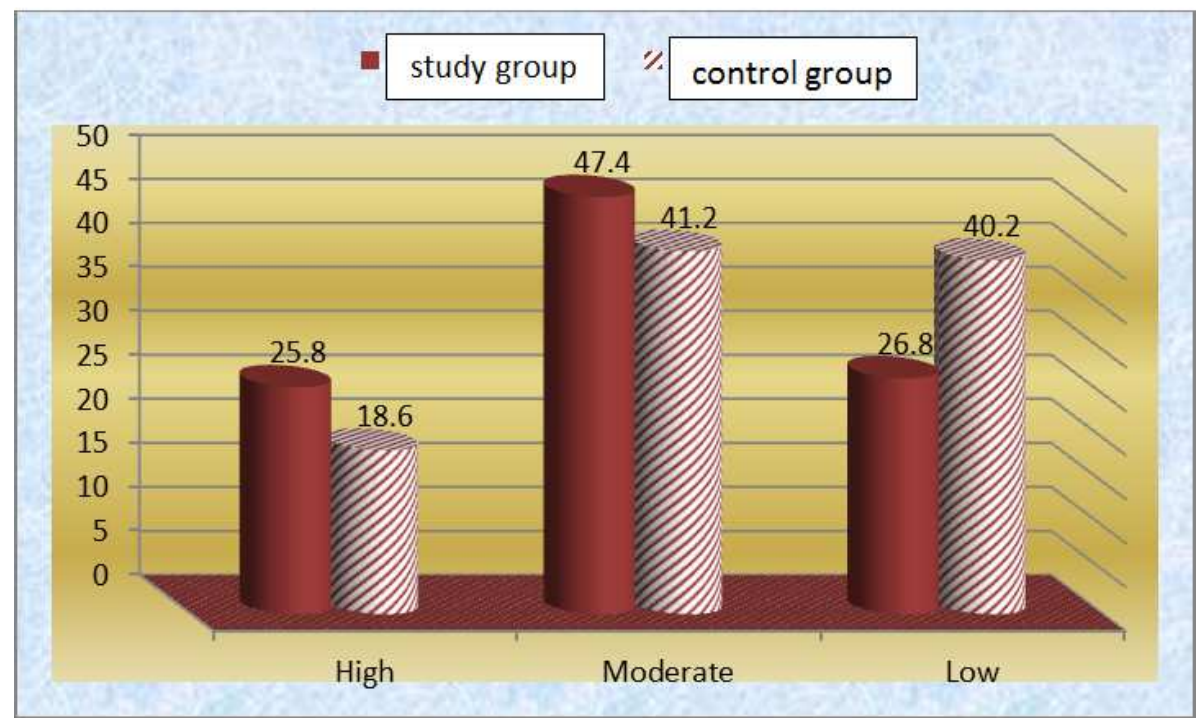

Figure 3. Frequency distribution of studied women (control and study group) regarding total childbirth empowerment scores before implementation.

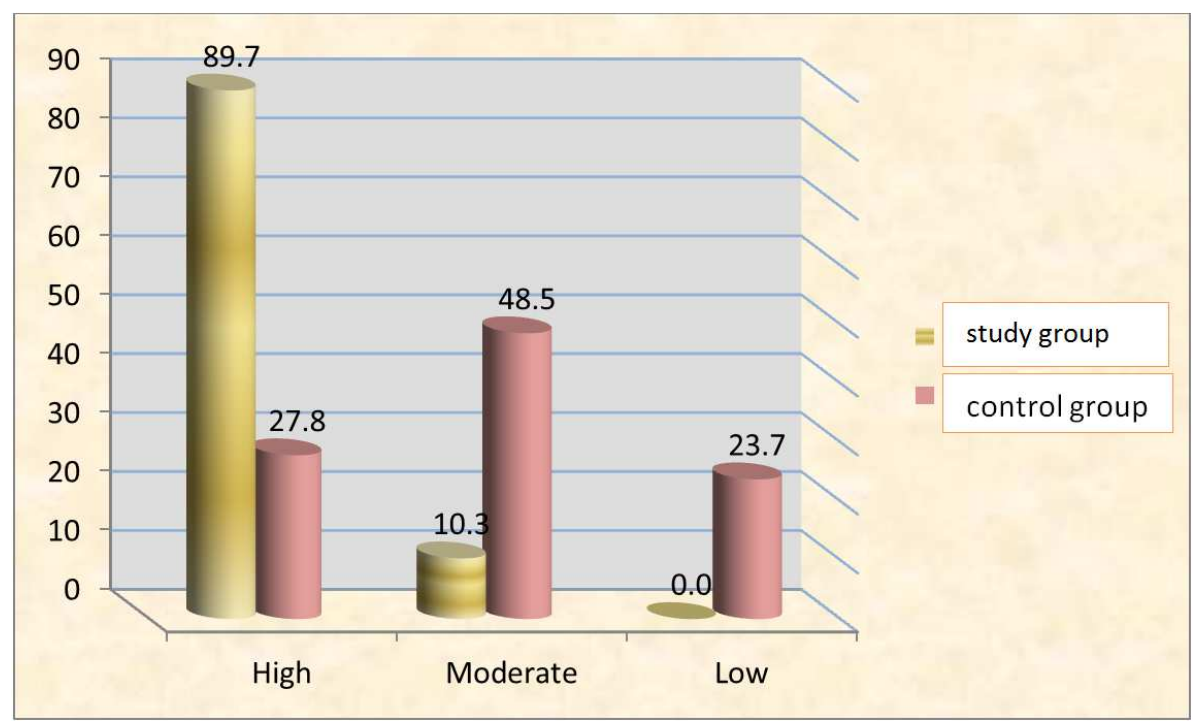

Figure 4. Frequency distribution of studied women (control and study groups) regarding total childbirth empowerment scores after the intervention.

\section{Discussion}

A birth plan is a document containing a woman's preferences and expectations about her childbirth process which targeting has given care toward promotion birth outcomes [1]. A key element of implemented birth plan care is empowering women to make informed decisions about health care through health education, direct communication, and a power-sharing women-health care provider relationship [22], therefore the present study was conducted to implement a birth plan and evaluate its effect on women childbirth outcomes and empowerment. The study findings supported the research hypotheses.

The findings of the current study showed no statistically significant differences between the control and study groups concerning age, educational level, occupation, residence and gestational age at enrollment data $(p>0.05)$ which means both groups were homogenous. These findings were similar to those reported by (Hodnett, 2015) [23] in a study conducted in Egypt titled " Effect of implementing a birth plan on women s' childbirth experiences and maternal \& neonatal outcomes " and revealed that there was no significant difference of the general characteristics of women among the intervention group and control group.

Performing obstetric practices during childbirth based on designed birth plan which followed the recommendations of WHO and Ministry of Health has made sure that the policy had been established in the hospital [24]. Concerning characteristic of childbirth, there were highly significant difference in most items of designed birth plan care during 1 st, 2nd and 3rd stage between control and study group ( $\mathrm{P} \leq$ 0.001). these results are consistent with [25] who found in a randomized cluster study titled the effectiveness of birth plans in increasing use of skilled care at delivery that women in the intervention group of the study reported higher implementation of the most elements of the birth plan during childbirth than the women in the control group with highly 
significant difference $(\mathrm{P}<0.001)$.

Also, these results agreed with [26] who stated that there is extensive evidence that women whom written birth plan showed an increase of a range of intrapartum interventions during stages of delivery including continuous fetal monitoring, pain management, and late oxytocin administration, as well as are more likely to have a spontaneous vaginal birth. The present findings could be showed that birth plans serve a guide for obstetrician and maternity nurses to deliver optimized health care throughout the childbirth process and additionally correct their misconceptions that women with birth plans have unrealistic expectations with no adding value to childbirth outcomes.

Regarding childbirth outcomes after implementing the birth plan, the current findings portrayed there was a significant decrease in mean \pm SD of 1st stage duration and the total duration of childbirth stages of the study group comparing to the control group as $(\mathrm{P} \leq 0.05)$. These results are similar with [23] that documented statistically significant difference between control \& intervention groups regarding duration of the stages of labor with the mean of $(23.6 \pm 4.8)$ hours in intervention group compared to $(27.4 \pm 9.7)$ hours in the control group, while these results discordance with [27] who found no difference between women with a written birth plan and those without regarding the length of any phase or stage of labor in a prospective, non-randomized controlled trial women with and without a written birth plan who lived in Houston, U.S. This difference mainly due to differences of two study places as in [27] study obstetric interventions of delivery applied for both groups once $1^{\text {st }}$ stage started while in our Egyptian hospitals, the women were received childbirth care once they are in active phase of $1^{\text {st }}$ stage that what birth plan compensated it by theoretical instructions during latent phase via telephone communications with study group beside well preparations for childbirth.

Concerning maternal outcomes, the current results portrayed that the majority of study group delivered vaginal delivery comparing to two-thirds of control group, the majority of study group had satisfactory experience of childbirth compared to about two-fifths of control group and only $17.8 \%$ of the study group had complications comparing to $27.8 \%$ of the control group with highly statistically significant difference $(\mathrm{P} \leq 0.001)$

The mentioned results were congruent with the following study findings as [28] who reported in a study titled "obstetrical outcome in women with self-prepared birth plan" that there was significance drop in the intrapartum Csections, a study of [1] who investigated the perspectives of expectant women and health care providers on birth plans and documented that birth plans can enhance the experience of delivery if women understand that unexpected circumstances that can arise during delivery and felt consistent with the birth plan, besides [29] who documented the higher satisfactory experience scores after delivery of the intervention group who use a standardized birth plan in compared to the control ones.

Also [2] added that reassuringly, having a birth plan was not associated with an increase in the rate of perineal lacerations or postpartum hemorrhage which could be considered dependent on obstetrical interventions. And [30] summarized that childbirth preparations programs and birth plans provide medical \& social support according to women's needs that promoted best birth experiences and lessened the occurrence of potential complications during or after deliveries.

As regarding to fetal outcomes, the current findings documented that the majority of study and control groups $(77.3 \%, 71.1 \%)$ respectively had normal Apgar score after childbirth and the baby weight of the study and control groups were relatively similar and normal weight. These findings go in the line with [1] result that reported there was no difference regarding Apgar scores (1- or 5-minute) or birth weight of both groups $(\mathrm{P}=.69)$. And [26] highlighted that studies do not show any differences in the Apgar test or baby weight between newborns of mothers with or without a birth plan, while the current findings disagree with [31] findings that showed the higher compliance of the birth plan of, the better the Apgar score and more normal baby weight ranges. This difference may be due to the last study showed the compliance of standardized birth plan interventions since 2004 as routine care in Spain third-level public hospitals which established earlier and comprehensive childbirth preparations and additionally favors more positive birth outcomes.

The results of the current study proved that there was no statistical significance was observed among the control and study groups regarding birth-related empowerment scale items before interventions $(\mathrm{P}>0.05)$. While there was highly statistical significance difference increase among study group compared to control group regarding most items of birthrelated empowerment scale after intervention as $(\mathrm{P} \leq 0.001)$ as well as $(89.7 \%)$ of the study group had high total birth plan empowerment scores compared to (57.8\%) of the control group. These findings are agreed with [32] which examined the impact of women's empowerment on reproductive health outcomes in Egypt and showed that educating women about childbirth preparations and participating in domains of care will enhance women's empowerment toward favorable health outcomes. And similar to a result of a study aimed to analyze how the birth plan provided female empowerment during labor and delivery and presented that the construction of a birth plan increased the empowerment of women in the process of parturition [33].

Besides [34] added in a study of birth preparedness and complication readiness among pregnant women attending antenatal care services that pregnant mothers who were knowledgeable about childbirth process were 2.9 times more likely to prepare for birth as compared to those who were not knowledgeable (AOR: 2.9; 95\%CI: 0.04-0.81) and reported less the obstetric complications, and also [35] demonstrated that birth plan educational content had an indirect effect on higher levels of empowerment and birth preparedness of women during delivery. This attributed to the fact when 
provided the opportunity for women to be knowledgeable and aware of their childbirth process, they gained more confidence and empowerment-related childbirth and also due to the effect of implemented birth plan educational and planned care to raise women empowerment.

From the above findings, it has shown achieving of the study hypotheses that consequently summarized the benefits of birth plan as an effective tool to favor a more natural and physiological childbirth process, better maternal \& neonatal outcomes and greater women empowerment which were in the same line with different methodological studies as [36]. Who concluded that the benefits derived from the use of the birth plan is as it an educational tool stimulates the discussion, obtaining of information, improves women's empowerment and promotes women sense of control during the childbirth process and [37] guidelines recommended that the positive effects of using the birth plan are to promote good practices in the care of delivery and childbirth and therefore, favor the improvement in the quality of maternal and child health care.

\section{Conclusion}

The implementation of birth plan has a significant effect on childbirth outcomes and women empowerment as the birth plan reported a higher implementation of designed childbirth care and a better effect on childbirth (duration, maternal and fetal) outcomes among the study group compared to control group. Also there was a highly significant increase in the total childbirth empowerment scores after implementing birth plan $(\mathrm{p}<0,001)$ in the control group compared to control group. Therefore, the research hypotheses are accepted.

\section{Recommendations}

Based on the findings of the current study, the following recommendations are suggested:

1. Raising awareness of healthcare staff of the outpatient clinic, delivery ward to implement birth plan toward increasing childbirth empowerment.

2. Hospital policies are needed to encourage the implementation of standardized birth plans to improve quality of maternity care.

Further studies are needed to

1. Investigate the degree of compliance after implementing a birth plan in official hospitals.

2. A similar study can be conducted for multiparous women.

\section{Acknowledgements}

The authors of the study are indebted to the delivery health care staff (obstetrician \& maternity nurses) for supporting our study. Particularly, we are indebted to the women who participated in our study, without whose participation in this study would not have been possible.

\section{References}

[1] Aragon, M., Chhoa, E., Dayan, R., Kluftinger, A., Lohn, Z., \& Buhler K. (2013). Perspectives of expectant women and health care providers on birth plans. Journal of Obstetrics and Gynaecology Canada (JOGC), 35 (11), 979-985. DOI: 10.1016/S1701-2163 (15) 30785-4.

[2] Afshar, Y., Mei, J., Gregory K., Kilpatrick, S., Esakoff, T. (2017). Birth plans impact on mode of delivery, obstetrical interventions, and birth experience satisfaction; A prospective cohort study. Wiley birth issues in pregnancy care journal, 45 (43), p 49@ 2017 Wiley Periodicals, Inc. Birth, 2018 https://doi.org/10.1111/ birt.12320.

[3] Welsh, J. and Symon, A. (2014). Unique and Preform Birth Plans; A Qualitative Exploration of Midwives' Experiences. Midwifery 30 (7), P95 DOI: 10.1016/j.midw.2014.03.004.

[4] World Health Organization (WHO) (2016). Care in normal birth; a practical guide [Internet]. Available from: http://apps.who.int/iris/bitstream/10665/63167/1/WHO_FRH_ MSM_96.242016.pdf.

[5] Pennell, A., Salo-Coombs, V., Herring, A., Spielman, F., (2011). Anesthesia and analgesia-related preferences and outcomes of women who have birth plans. Journal of Midwifery \& Women's Health 2011; 56, 376-381. doi: 10.1111/j.1542-2011.2011.00032.

[6] Kuo, S., Lin, K., Hsu C., Yang C., Chang M., Tsao C., (2014). Evaluation of the effects of a birth plan on Taiwanese women's childbirth experiences, control and expectations fulfillment: a randomized controlled trial. International Journal of Nursing Studies, 47: 806-14. DOI: 10.1016/j.ijnurstu., Available from; https://www.ncbi.nlm.nih.gov/ pubmed/20036361.

[7] Cook, K., Loomi, s C. (2012). The Impact of Choice and Control on Women's Childbirth Experiences. Journal of Perinatal Education, 21 (3): 158-168. DOI: 10.1891/10581243.21.3.158

[8] Udofia, E., Obed, S., Calys-Tagoe, B., Nimo, P. (2013): Birth and Emergency Planning: A Cross-Sectional Survey of Postnatal Women at Korle $\mathrm{Bu}$ Teaching Hospital, Accra, Ghana. African Journal of Reproductive Health, 17 (1): 27-40.

[9] Holmstrom, I., \& Roing, M., (2010): The Relations of Patient Empowerment; a Discussion on Concepts. Patient Education Counseling, $79 \quad$ (2), 167-172, 2010. DOI: 10.1016/j.pec.2009.08.008.

[10] Miedema, S., Haardörfer, R., Girard, A., Yount, M. (2018). Women's empowerment in East Africa; development of a cross-country comparable measure. World Dev, https://doi.org/10.1016/j.worlddev.2018.05.031.

[11] Alsop, R. and Heinsohn, N., (2017): Measuring empowerment in practice: structuring analysis and framing indicators: World Bank Publications, https://elibrary. worldbank.org/doi/abs/10.1596/18139450-3510, Accessed 05 Aug 2017.

[12] Suárez, M., Armero-Barranco, D., Canteras, M., MartínezRoche E. (2015). Use and influence of Delivery and Birth Plan in the humanizing delivery process. Rev. Latino-Am Enfermagem J., 23 (3), p 520-6, Available from https://www.ncbi.nlm.nih.gov/pubmed/26155015. 
[13] Shi, Y., Wang, D., Yuan Y., Jiang, Y., Zeng, Q., Chang, C. (2015). The effect of prenatal education curriculum on the mother's prenatal examination utilization, delivery mode, and recovery status. Environmental Health Prevention Medicine, 20, p: $397-403$.

[14] Byerley, B. \& Haas, D. (2017). A Systematic Overview of the Literature Regarding Group Prenatal Care for High-Risk Pregnant Women. BMC Pregnancy Childbirth, 17 p: 3.4.

[15] Fleming, S., Smart, D., \& Eide, P. (2011). Grand multiparous women's perceptions of birthing, nursing care, and childbirth technology. Journal of Perinatal Education, 20 (2), 108-117. DOI: $10.1891 / 1058-1243.20 .2 .108$.

[16] Ringdal, M., Chaboyer, W., Ulin, K. (2017). Patient preferences for participation in patient care and safety activities in hospitals. BMC Nursing, 16 (69) https://doi.org/10.1186/s12912-017-0266-7.

[17] Mahmoud, G., Omar, M. (2018). Women's awareness and perceptions about maternal mortality in rural communities in Assiut and Fayoum Governorates, Egypt. Egyptian Nursing Journal, [cited 2019 Oct 5], 15: 21-9. Available from: http://www.enj.eg.net/text.asp?2018/15/1/21/240350.

[18] Kaso, M., Addisse, M., (2014). Birth preparedness and complication readiness: a cross-sectional study, Reprod Health, 11 (55): 1-12

[19] Ndeto, J., Barasa S., Murigi M., Keraka M., Osero J. (2018). Utilization of individual birth plan during pregnancy and its determinants in Makueni County. International Journal of Community Medicine and Public Health, Vol 5 (1), Page 305 (1): $30-37$.

[20] Jahdi, F., Montazeri, A., Balouchi, M., Behboodi, M. (2014). The impact of group prenatal care on pregnant women empowerment, Payesh, 13 (2): 229- 234 (Persian).

[21] American colleagues of nurses-midwives (2014). Writing a Birth Plan, Volume 59, No. 2, the Journal of Midwifery \& Women's Health, p226-228, 1526-9523/09/\$36.00 DOI: 10.1111, Jewish, www.sharewithwomen.org.

[22] Klima, C., Vonderheid, S., Norr, K., Park, CH. (2015). Development of the Pregnancy-related Empowerment Scale, Nursing and Health, 3 (5): 120-127, http://www.hrpub.org.

[23] Farahat, A., Mohamed, H., Elkader, A., \& El Nemer, A. (2015). Effect of implementing a birth plan on women's' childbirth experiences and maternal \& neonatal outcomes. Journal of Education and Practice, 6 (6), 24-31.

[24] Hodnett, E., Downe, S., Walsh, D., 2015. Alternative versus conventional institutional settings for birth. Cochrane Database Syst Rev, [2] 9, Disponível em: http://cochrane.bvsalud.org/doc.php?db=reviews\&id=CD0000 12 .

[25] Magoma, M. Requejo, J. Campbell, O., Cousens, S., Merialdi, $M$. and Filipp V. (2013). The effectiveness of birth plans in the increasing use of skilled care at delivery in rural Tanzania. Tropical Medicine and International Health journal, volume 18 no 4 pp 435-443 April 2013 (C) 2013 Blackwell Publishing Ltd.
[26] Li, Y., Townend, J., Rowe, R., Knight, M., Brocklehurst, B., Hollowell, J. (2014). The effect of maternal age and planned place of birth on intrapartum outcomes in healthy women with straightforward pregnancies. BMJ Open, 4, (40), p26, DOI: 10.1136/ BMJ open -2013-004026.

[27] Davis, B., Clark, S., McDonald, K., Young, T., Swaim, L. (2019). The impact of a birth plan on maternal and neonatal delivery outcomes, American Journal of Obstetrics \& Gynecology, vol 22 (3), 309, ajog.org.

[28] Hadar, E., Raban, O., Gal, B., Yogev, Y., Melamed, N. (2012). The obstetrical outcome in women with a self-prepared birth plan. Maternal-Fetal Neonatal Medicine Journal, 25 (10), p: 2055.

[29] Anderson, CM., Monardo R., Soon R., Lum J., Tschann M., Kaneshiro B. (2017). Patient communication, satisfaction, and trust before and after use of a StandardizedBirth Plan. Hawaii J Med Public Health. 2017 [cited 2018 Jan 14]; 76 (11): 3059. Available from: https://www.ncbi.nlm.nih.gov/ pmc/articles/PMC56 94973.

[30] Ngai F., Chan, S., Ip, W. (2019). The effects of a childbirth psycho-education program on maternal role competence and perinatal depression; a quasi-experiment. International Journal of Nursing Studies, 46 (5), p1298.

[31] Hidalgo-Lopezosa, P., Hidalgo-Maestre, M., Rodríguez M. (2013). Birth plan compliance and its relation to maternal and neonatal outcomes. Rev Latino-Am Enfermagem, 201 (25) 2p: 953. DOI: https://doi.org/10.1590/1518- 8345.2007.2953

[32] Samari, G., (2017). First birth and the trajectory of women's empowerment in Egypt. BMC Pregnancy Childbirth, 17 (2), p: 362, DOI 10.1186/s12884-017-1494-2.

[33] Mouta, R., Silva T., Melo, P., Lopes, N., Moreira, V. (2017). Plano de part Como estratégia de empowerment feminine, Rev Baiana Enferm, $31 \quad$ (4), e20275. DOI: https://doi.org/10.18471/rbe.v31i4.20275.

[34] Hailemarim, A., Nahusenay, H., Ghana, E., Abebe, A., Getaneh, B. (2016). Birth Preparedness and Complication Readiness among Pregnant Women Attending AntenatalCare Services at Public Health Facilities. Global Journal of Medical Research, 16, p231, Link: https://tinyurl.com/y5hj3swp.

[35] Shimamoto K, Gipson J. (2017). Examining the mechanisms by which women status and empowerment affect skilled birth attendant use; Modeling approach. BMC Pregnancy Childbirth, 17 (Suppl 2)

[36] Divall, B., Spiby, H., Nolan, M., Slade, P. (2017). Plans, preferences or going with the flow; an online exploration of women's views and experiences of birth plans. Midwifery, 54 (29), p-34. DOI: https://doi.org/10.1016/j.midw.2017.07.020.

[37] (WHO) (2018). recommendations: intrapartum care for a positive childbirth experience. Geneva: [cited 2018 Apr 11], Available from: http://apps.who.int/iris/bitstream/handle/10665/260178/97892 41550215eng.pdf; jsessionid=85C6F3DF79F8B5F4B476076B 28785A8A?sequence. 